\title{
A Classroom Research Skills Development of Suan Sunandha Rajabhat University' Students by Research Based Learning
}

\author{
C. Waree, K. Ontkwanmuang, and P. Chanfoy
}

\begin{abstract}
This research aims to utilize the research based learning in reinforcing classroom research skills, and to study on a classroom research skills development of Suan Sunandha Rajabhat University's students by research based learning. The target group was 214 students in the 2nd semester of Academic Year 2013. The target group was selected by using purposive Sampling. The researchers were the instructors of the 2nd year students and 3 subjects including Thai, English, and mathematics. The tool used in this experiment was learning management plan, 25 items of Pre-test and Post-test, and work evaluation. The obtained data was analyzed by calculating the percentage of grades and scores of classroom research skills, t-test, and qualitative data. The results showed that there were 204 students who passed the criteria with $\mathrm{C}+$ Grade and higher calculated to be $95.33 \%$. In overall, the scores of three dimensions of classroom research skills were in the highest level with the mean of 11.84, and deviation of 0.78 . The scores of Post-Test was higher than that of Pre-test with $t=43.01$ and statistical significance at $\mathbf{0 5}$.
\end{abstract}

Index Terms-A classroom research skills, research based learning, teaching, higher education.

\section{INTRODUCTION}

Section 24 (5) of Article 4 of National Education Act B.E. 2542 states that "Enable instructors to create the ambiance, environment, instructional media, and facilities for learners to learn and be all-round persons, able to benefit from research as part of the learning process. In so doing, both learners and teachers may learn together from different types of teaching-learning media and other sources of knowledge." and Section 30 states that "Educational institutions shall develop effective learning processes. In doing so, they shall also encourage instructors to carry out research for developing suitable learning for learners at different levels of education [1]".

Research based learning is considered as the key of the graduates because it is the learning emphasizing on self-directed learning of learners. It is the development of knowledge acquisition process and the test of self-study of learners. Instructional model was divided into 4 major aspects including research-based instruction, Under Study Concept, instruction that the learners study from research of instructors and leading researchers in the studied fields, and instruction with support of the results from research [2].

Manuscript received December 1, 2014; revised July 22, 2015

The authors are with the Faculty of Education of Suan Sunandha Rajabhat University, Thailand (e-mail: chaiwat.wa@ssru.ac.th, kancheera.on@ssru.ac.th, poonyapon.ch@ssru.ac.th).
From the current educational management guidelines, it was found that instructional mainly emphasized on the learners by promoting the learners to play the role in self-directed learning and able to think, do, and solve problems. For Bachelor of Education Program, it is the program emphasizing on theories and practices in order to enable students to apply knowledge to actual practice in the educational period of each subject of the program. All subjects of Bachelor Education Program are consisted of contents and theories emphasizing on analysis by collecting the actual data for analysis in order to exchange learning among learners. As a result, it is the opportunity for instructional management by analyzing the contents in order to discover the instructional processes and expected learning results. Learning development by research based learning is another alternative helping to promote learner's learning. In addition to gaining knowledge, students also gains the skills of analytical thinking, problem solving, participating in problem solving, and other skills practicing. As a result, the instructors take it as an opportunity to develop learning by research based learning [3].

Research-based learning (RBL) is a multifaceted approach for orchestrating a variety of learning and teaching strategies in order to connect research and instruction. This chapter presents a theoretical insight into RBL and teaching which integrates learning, teaching, and research. Further, a curriculum for descriptive and inferential statistics using the $\mathrm{RBL}$ and teaching approach is introduced. The chapter wraps up with reflections on further implementation of RBL and teaching, including the adoption of new technologies to assist this important approach of university education [4].

Research-based learning provides training and practice for students in a number of broad learning objectives: 1) how to pose a research question; 2) how to test the question; 3 ) how to present research findings; and 4) how to practice research integrity. Not all students can join a full-time undergraduate research experience, but most classes can be structured to teach elements of research. Research skills are not learned solely by observation, but need to be taught, practiced, and critiqued. Assignments illustrated in this chapter may take as little as 5-10 min or may be expanded to become major components of a class. Research skills are useful for every student, and the reinforcement of research skills should be at multiple levels from course or lesson organization to use of learning objectives and grading rubrics, to consistency in how the instructor models research standards [5].

Research undertaken by educational researchers based in universities has not had the desired impact on the practices of 
classroom science teachers. Educator has argued that if teaching is to be recognised as a profession there is a great need for the marrying of the knowledge of the practitioner with that of the researcher. Student teachers might learn to respect the potential for such a union by undertaking minor classroom research projects during their teacher preparation programs. This paper discusses the role of research projects in pre-service teacher preparation with reference to an inquiry conducted with teacher education students [6].

The four formats of a classroom research skills development of Suan Sunandha Rajabhat University's students by research based learning emphasized on instructional integration, instructional techniques by using research based learning during the 1 st semester in the subjects that the researchers had the class schedules. It was prepared as the concrete instructional plan because most instruction in university level had no instruction plan with complete elements. There was only Course Syllabus (TQF.3) specifying only the topic of each weekly class. Since most of instruction was consisted of lecture method, research based learning was the method to foster research skills and integrate with content of those subjects contributing students to have profoundness in instructional management with research skills in all aspects. In addition, the students were also able to apply the obtained skills for solving all problems in their daily life and manage instruction and class research when they had to practice teaching and work as the teachers.

\section{OBJECTIVES}

- To apply the research based instruction to reinforce the classroom research skills of of Suan Sunandha Rajabhat University' Students.

- To study on the classroom research skills development of of Suan Sunandha Rajabhat University' Students by research based learning.

\section{SCOPE OF RESEARCH}

The target group of this research was 214 Suan Sunandha Rakabhat University in all year classes obtained from purposive sampling. The researchers were 214 instructors of the 2 nd year students and 3 subjects including Thai, English, and mathematics in the 2nd semester of Academic Year 2013.

\section{EXPECTED BENEFITS}

- To obtain the guidelines on research based instructional management.

- Students had interest and learning achievement in the studied subjects with utilization of research based instructional management.

- Knowledge gained from this research would be useful for instructors and anyone interested in developing research skills of other subjects.

\section{RESEARCH FRAMEWORK AND CONCEPT}

Research framework and concept is shown in Fig. 1.

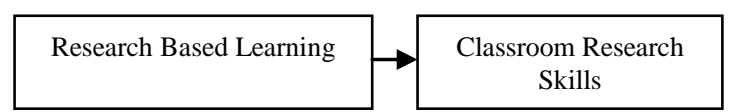

Fig. 1. Research framework and concept.

\section{RESEARCH PROCESSES}

The target group was selected by using purposive sampling and the researchers were 360 instructors of the 2nd year students and 3 subjects including Thai, English, and mathematics in the 1nd semester of Academic Year 2013. According to the curriculum of Bachelor Degree of Education program, the students had to study research course in the 4th year and the 5th year students had to conduct one classroom research project per one student. In overall, the results of the classroom researches of the students were poor quality and huge obstacle for students and their advisors. There may be several causes of such obstacle. However, one major cause was that only one class of classroom research in the $4^{\text {th }}$ year was insufficient for fostering research processes in students. As a result, the researchers wished to study on the behaviors of students deeply as well as providing research based learning to the targeted students.

Most instructions of university level had no instructional plan with complete elements. There was only Course Syllabus (TQF.3) specifying only the topic of each weekly class. Since most of instruction was consisted of lecture method, the researchers selected research based instruction with the following elements: Title, principles and reasons, expected results, contents, subject matters, learning activities (Introduction, activity operation, and conclusion), learning media, learning resources, measurement and assessment, knowledge insert, exercise paper. In each instructional management plan, it was consisted of research based instruction by integrating and inserting in learning activities, i.e., 1) research-based instruction; 2) Under Study Concept; 3) instruction that the learners study from research of instructors and leading researchers in the studied fields; and 4) instruction with support of the results from research. This type of instruction emphasized on building three research skills out of 5 research skills including: 1) research problem determination; 2) Determination of problem solving or hypothesis; 3 ) investigation and data collection. There were totally 16 instructional plans with 3 class hours per each instruction plan.

The results were assessed and measured authentically by observing, questioning, and evaluating Rubric Score and the obtained feedback was provided to the students. The researchers provided the students independence in creating their works while the researchers would act as the advisor giving the students guidelines for studying, searching, and creating knowledge by themselves. The researchers collected data and recorded development of students in each class period in Post-Lesson Report. In addition, the researchers also studied development of research skills of the students during the semester. Classroom research skills were consisted of: 1) Research problem determination; 2) Determination of problem solving or hypothesis; 3) Investigation and data collection; 4) Data analysis and synthesis; 5) Conclusion and research report. This research focused on three research skills only including: 1) Research problem determination; 2) 
Determination of problem solving or hypothesis; 3) investigation and data collection, because all skills require more time for development.

After semester, students' knowledge and understanding of each subject would be measured and their classroom research skills were measured through 60 items of objective test and the student's work assessment was in the form of Rubric Score.

The obtained data was analyzed and synthesized quantitatively and qualitatively exhibiting data in the form of lecture and graph showing development of classroom research skills of students. Subsequently, the research report was written.

\section{CONCLUSION}

TABLE I: THE STUDENTS ACHIEVEMENT

\begin{tabular}{|c|c|c|c|c|c|c|c|c|}
\hline \multirow{2}{*}{$\begin{array}{l}\text { Subjec } \\
\mathrm{t}\end{array}$} & \multicolumn{8}{|c|}{ G.P.A } \\
\hline & A & A- & $\mathrm{B}+$ & B & B- & $\mathrm{C}+$ & I & $\mathrm{F}$ \\
\hline $\begin{array}{l}\text { Subjec } \\
\text { t1 }\end{array}$ & 10 & 3 & 3 & 2 & 1 & 2 & 2 & - \\
\hline $\begin{array}{l}\text { Subjec } \\
\mathrm{t} 2\end{array}$ & 42 & 4 & 2 & - & - & - & - & - \\
\hline $\begin{array}{l}\text { Subjec } \\
\mathrm{t} 3\end{array}$ & 42 & 33 & 31 & 29 & & & & 8 \\
\hline Sum & 94 & 40 & 36 & 31 & 1 & 2 & 2 & 8 \\
\hline $\begin{array}{l}\text { Percen } \\
\text { tage }\end{array}$ & $\begin{array}{l}43 . \\
93\end{array}$ & $\begin{array}{l}18 . \\
69\end{array}$ & $\begin{array}{l}16 . \\
82\end{array}$ & $\begin{array}{l}14 . \\
49\end{array}$ & 0.47 & 0.93 & 0.93 & 3.74 \\
\hline
\end{tabular}

Most students were enthusiastic and interested in research based learning for reinforcing their classroom research skills. The instructors also inserted the integration in the activities upon differences of contents in each subject, i.e., 1) the instructors applied the research results to their instruction; 2) the learners applied the research results to their learning; 3) the instructors applied research processes to instruction; 4) the instructors applied research processes to learning. There were 204 students who got $\mathrm{C}+$ and higher calculated to be $95.33 \%$ while 10 students got A calculated to be $43.93 \%$. However, there were 10 students who failed to meet the criteria calculated to be $4.67 \%$. From interviewing with the students who failed to meet the criteria, it was found that they failed to hand on their work completely and they were also absent from class. As a result, their accumulated scores were less than that defined by criteria. In addition, they also gained low scores from the final exam as well (see Table I to Table IV).

Results of classroom research skills development:

- For research problem determination, the students were able to determine the research problem properly and clearly with appropriate coverage and possibility that was different from the beginning that they had no idea where to start their researches or narrow or expand the problem excessively.

- For hypothesis, the students were able to assume the hypothesis correctly with direction and accountability. They also had group discussion in order to show their hypothesis assumption.

- For data collection, the students searched and collected data and divided their work individually. In addition, they also searched for data by using web-based search engine and library. They concluded the discovered issues and their references with link (for connecting) to new data resources.

- For the research results on student's classroom research skills score in 3 overall pictures, it was found that they were in the highest level with the mean of 11.84 and deviation of 0.78 . Their ability on problem determination was in high level with the mean of 10.51 and deviation of 1.34. Their hypothesis assumption was in the highest level with the mean of 11.91 and deviation of 0.79 . Data collection was in the highest level with the mean of 13.11 and deviation of $0.80, t=43.01$. Their scores of the Post-test were higher than those of Pre-Test with statistical significance at .05 .

TABLE II: PAIRED SAMPLES STATISTICS

\begin{tabular}{ccccc}
\hline \hline & Mean & $N$ & $\begin{array}{c}\text { Std. } \\
\text { Deviation }\end{array}$ & $\begin{array}{c}\text { Std. Error } \\
\text { Mean }\end{array}$ \\
\hline pre & 15.4860 & 214 & 1.66355 & .11372 \\
post & 20.3037 & 214 & 1.15725 & .07911 \\
\hline \hline \multicolumn{5}{c}{ TABLE III: PAIRED SAMPLES CORRELATIONS } \\
\hline \hline & & $N$ & Correlation & Sig. \\
\hline pre \& post & 214 & .369 & .000 \\
\hline \hline
\end{tabular}

TABLE IV: PAIRED SAMPLES TEST

\begin{tabular}{|c|c|c|c|c|c|c|c|c|}
\hline & \multicolumn{5}{|c|}{ Paired Differences } & \multirow{3}{*}{$t$} & \multirow{3}{*}{ df } & \multirow{3}{*}{ Sig. (2-tailed) } \\
\hline & \multirow[t]{2}{*}{ mean } & \multirow[t]{2}{*}{ S.D. } & \multirow{2}{*}{$\begin{array}{l}\text { Std. } \\
\text { error }\end{array}$} & \multicolumn{2}{|c|}{$\begin{array}{l}\text { 95\% Confidence Interval of the } \\
\text { Difference }\end{array}$} & & & \\
\hline & & & & low & up & & & \\
\hline pre - post & -4.81 & 1.64 & .11 & -5.04 & -4.60 & -43.01 & 213 & .000 \\
\hline
\end{tabular}

\section{DISCUSSION}

Most students were enthusiastic and interested in research based learning for reinforcing their classroom research skills. The instructors also inserted the integration in the activities upon differences of contents in each subject, i.e., 1) the instructors applied the research results to their instruction; 2) the learners applied the research results to their learning; 3) the instructors applied research processes to instruction; 4) the instructors applied research processes to learning. There were 204 students who got $\mathrm{C}+$ and higher calculated to be
$95.33 \%$ while 10 students got A calculated to be $43.93 \%$. However, there were 10 students who failed to meet the criteria calculated to be $4.67 \%$. This was because the researchers mutually held the meeting to find the guidelines on research and instructional management and research leading to the same direction of research operation. The obtained results were measured authentically by using assessment and various tools. As a result, most students' grades were in excellent level and met with the criteria. This was consistent with the study conducted by Somrak Sumeth $e t$ al. They conducted a research on instructional management 
by research based learners that was the case study of Our Lady of Perpetual Help School. The results showed research based instructional management was consisted of 4 elements including teacher's instructional processes, teacher's roles, learner's learning processes, and learning results [7]. In addition, the results of this research were also consistent with Holdsworth (2004)'s work studying on the results of research based instruction in distance learning of Drama students. The learners had to learn on theoretical and practical parts through project proposal preparation and stage performance. The instruction of this research gave the Learners opportunities to select their own interested project's topics while the instructors acted as the advisors. In addition, information technology was also utilized for supporting the instruction [8].

For the results of classroom research skills score of the students, the overall pictures of three dimensions were in the highest level with the mean of 11.84 and deviation of 0.78 . The score of these dimensions were obtained from students' works assessment and evaluation on students' behaviors expressed during the research based instruction. Their ability on problem determination was in the highest level with the mean of 10.51 and deviation of 1.34. Their hypothesis assumption was in the highest level with the mean of 11.91 and the deviation of 0.79 . Data collection was in the highest level with the mean of 13.11 and deviation of $0.80, t=43.01$. Their scores of Post-Test was higher than those of Pre-Test with statistical significance at .05 that was consistent with the research of Pranom Othakanon et al. who developed instruction by using research based instruction in nursing course for students of Bachelor of Nursing Science Program. The results showed that the students were able to seek for answers systematically in high level. The students were also satisfied with instructional development by using research based instruction in high level [9]. In addition, the results of this research were also consistent with those of Spronken-Smith et al. who studied on enhancing the instructional value by using research based instruction that was the case study of exploring knowledge from the research project on pollution. It was the integration of research processes with instructional management in Bachelor Program. The samples were the 3rd year students who were studying Geographical Situation course. The results showed that the instructional value was able to be enhanced by using research based instruction and the students had to investigate and seek for knowledge of their responsibilities by participating in the research project with support team. The students had to perceive information from studying and collecting data daily and the duration of this research was 2 weeks. For assessment, it focused on group process and the assessment was performed in all stages in order to improve their operation commenced from project introduction. The value of the project was enhanced by enabling the students to understand the background and the origin of research based instruction for the program, learning on research processes, and analytical skill development [10].

\section{SugGESTIONS}

From this research, the researchers had the suggestions as follows:

\section{A. General Suggestions}

- There should be clarification, suggestions, and consulting provided to the students intermittently in order to enable them to understand in the content of the course correctly without excessive conduct. The students should be creative and performed the operation by themselves.

- There should be available time provide to the students for continuous practicing by reducing the duration of lecture in order to make the students to repeat their practice leading to higher expertise and skills of classroom research.

\section{B. Suggestions for Further Researches}

- The research based instruction should be used as the basement for other programs.

- This research developed the students to have the research skills on problem determination, hypothesis assumption, and data collection due to limited time therefore the skills on analysis and conclusion should be developed in further researches.

- There should be some researches on the permanence of classroom research skills of the students.

\section{ACKNOWLEDGMENT}

This research was supported by Suan Sunandha Rajabhat University and Higher Education Research Promotion (HERP) in Office of the Higher Education Commission. Special thanks you to all experts and students of SSRU who helped and supported this project.

\section{REFERENCES}

[1] R. Gazette, National Education Act B.E. 2542, Book No. 116, Part 74 Kor, 1999, pp. 21-29.

[2] K. Kularbphettong, P. Waraporn, and C. Tongsiri, "Analysis of student motivation behavior on e-learning based on association rule mining," World Academy of Science, Engineering and Technology, International Science Index 66, vol. 6, no. 6, pp. 471-474, 2012.

[3] K. Sungkhamanee, "Lodging business management in Nakhon Pathom with sufficient economy approach," International Journal of Social, Management, Economics and Business Engineering, vol. 7, no. 7, pp. 876-881, 2013.

[4] D. Ifenthaler and M. Gosper, Curriculum Models for the 21st Century, 2014, pp. 73-89.

[5] G. E. Wagner, Innovative Strategies for Teaching in the Plant Sciences, 2014, pp. 61-82.

[6] S. M. Ritchie, Research in Science Education, vol. 23, issue 1, pp. 236-242, 1993.

[7] S. Sumeth et al., "The learning of students with the research process: Case study of Bangkapi School and St. Louis School education," Bangkok: Pramandanijjanukroah School, 2004.

[8] N. Holdsworth, "Research in drama education," The Journal of Applied Theatre and Performance, vol. 12, issue 2, 2004.

[9] P. Othakanon et al., "Development of learning and teaching using research as a base course for nursing students to Nursing," Bangkok: Chulalongkorn University, 2008.

[10] S. Smith et al., "Inquiry-based learning: Meaning, theoretical basis and use in tertiary education," Report prepared for the Ministry of Education, p. 32, 2007.

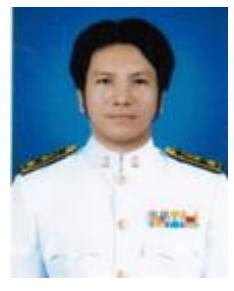

Chaiwat Waree was born in Nongchang, Thailand. $\mathrm{He}$ received the B.Ed. degree in Thai from the Srinakharinwirot University, Thailand in 1999, the M.Ed. degree in guidance and counseling psychology from the Srinakharinwirot University, Thailand in 2002, and the D.Ed. degree in curriculum and instruction from the Burapha University, Thailand in 2010. His research interests cover the pedagogy and 
psychology and education technology. Dr. Chaiwat is a lecturer at Faculty of Education, Suan Sunandha University and external assessor for Office of National Education Standards and Quality Assessment, Thailand.

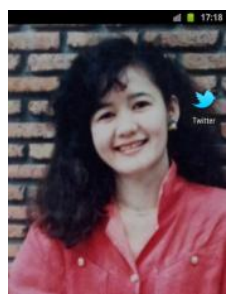

Kancheera Ontkwanmuang was born in Bangkok, Thailand. She received the B.Ed. degree in Thai from the Chandrakasem Rajabhat University, Thailand in 1985 and the M.Ed. degree in higher education from the Srinakharinwirot University, Thailand in 1995, Her research interests cover the pedagogy and higher education. Ms. Kancheera Ontkwanmuang is a lecturer at Faculty of Education, Suan Sunandha University.

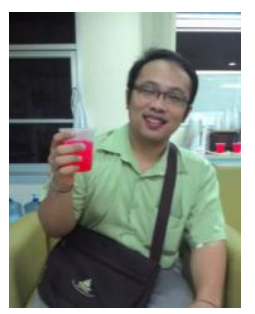

Poonyapon T. Chanfoy was born in Bangkok, Thailand. He received the B.Ed. degree in mathematics from the Bansomdejchaopraya Rajabhat University, Thailand in 2005, and the M.Ed. degree in mathematics from the Srinakharinwirot University, Thailand in 2009. His research interests cover the pedagogy and mathematics. Mr. Poonyapon T. Chanfoy is a lecturer at Faculty of Education, Suan Sunandha University. 